\title{
Nursing management and leadership approaches from the perspective of registered nurses in Portugal
}

\author{
Rita Fernandes*1, Beatriz Araújo², Fátima Pereira ${ }^{3}$ \\ ${ }^{1}$ Centro Hospitalar São João, Universidade Católica Portuguesa, Centro de Investigação Interdisciplinar em Saúde, Porto, \\ Portugal \\ ${ }^{2}$ Universidade Católica Portuguesa, Centro de Investigação Interdisciplinar em Saúde, Porto, Portugal \\ ${ }^{3}$ Faculdade de Psicologia e Ciências da Educação da Universidade do Porto, Porto, Portugal
}

Received: February 26, 2018

DOI: $10.5430 /$ jha.v7n3p1
Accepted: March 28, 2018

Online Published: April 8, 2018

\begin{abstract}
Background: The leadership role in nursing reflects the complexity and rapid transformations which take place in healthcare. The influences of this catalyst of change are important for nurses' identity and professional development, as well as for evolving and innovating nursing practices.

Objective: This study is part of a larger research project on doctoral Leadership in Nursing, aims to identify nurses' perceptions regarding their similarities and differences compared to nurses in manager roles, in order to understand and recognise the influences and barriers to leadership in the nursing hierarchy.

Methods: A descriptive cross-sectional study of a qualitative nature, involved the participation of 19 registered nurses (RNs), based on the Zavalloni Ego-Ecological Theory.

Results: From the dimension of identification emerged two major themes - the vision of the profession and the competency skills required. The major theme of competency skills includes subthemes of relational, technical/scientific, leadership and management competencies. From the dimension of differentiation emerged two major themes - the vision of the profession and the competency skills. The major theme competency skills included two subthemes - the deficit of relational and management competency skills. Conclusions: Nurse-managers may choose to distance or influence nurses; influence can be achieved through not only a combination of leadership and management competencies but also on the nurse-managers' evidence-based expertise and relational skills alongside a vision to support team unity in order to create a positive environment which encourages the nurses to be involved in high quality and innovative practices.

Implications for nursing management: This study may help to understand the approaches undertaken by leaders in nursing and subsequently enhance their performance. It may also inform future leadership training for nurses.
\end{abstract}

Key Words: Leadership, Management, Influences, Identity, Development, Care

\section{INTRODUCTION}

The constant change and complexity of health care environments presents challenges to identity as well as to the development of capacities to cope and work as a team. The leader stands out as working to provide an environment conducive to the development of the nursing professional and the nursing team. ${ }^{[1]}$

However, in the training process and in the functions of the

\footnotetext{
*Correspondence: Rita Fernandes; Email: fernandesrita107@gmail.com; Address: Centro Hospitalar São João, Universidade Católica Portuguesa, Centro de Investigação Interdisciplinar em Saúde, Porto, Portugal.
} 
nurse-manager, administrative aspects were overestimated to the detriment of leadership. ${ }^{[2]}$ Ideally, in line with organisational needs, the management and leadership functions would be combined equally, considering that a formal leader is recognised by their ability to simultaneously carry out the management and leadership roles. ${ }^{[1]}$

Leadership is defined as a relational, ethical, continuous, and dynamic process among people who desire a positive change as a group. ${ }^{[3]}$ Leadership is also associated with the process of influence over others, with important roles of implementation and innovation of health systems; with the commitment of nurses in the organisation and profession. This then leads to an increase in evidence-based practice and consequently to an increase in quality of care provided. ${ }^{[4]}$

Acknowledging the multiple management and leadership concepts and their implications for nurses and care, both from positive and negative angles. ${ }^{[5]}$ The purposes of this article are to identify nurses' differentiations and identifications with their superiors, and to understand the recognition of influences and distances to the leadership of the nursemanagers.

The Psychosocial Identity Inventory of Zavalloni \& LouisGuérin $^{[6]}$ allows access to the interactions between the individual and the collective. Through the inventory and contextualisation of the subject's history, in its real and imaginary memories, social representations, experiences and their relationship, we can recognise the identifications and differentiations of the subject in relation to a group. ${ }^{[5,7]}$

Knowing the affective qualities of the nurse-managers also provides an understanding of how the nurses associate or dissociate to these elements within the nursing teams. It is considered that the identification of one subject to another implies explicit and implicit consent in the construction and development of the subject's identity, providing not only professional development but also involvement and belonging to the professional group. Furthermore, the differentiation of one subject to another in the group allows us to identify a singular and collective identity as opposed to the intraprofessional group, which emerges from conflicts, counter values and exclusion from each other. ${ }^{[6]}$

The identifications and differentiations or oppositions of the nurse to the nurse-manager allow us to understand the influences of the formal leader, as well as the factors of distancing these influences.

It is the influences and approaches to leadership that we intend to value, to disseminate and expand these leaderships that act in the professional identity nucleus of these subjects and reduce or transform the factors of opposition to the professional influence of the subjects. In Portugal, the influences of the nurse-managers present their own specific topics and behaviors due to the transformation of the career. Prior to 2009, the nurse-manager role was advertised, and an individual was chosen for the role based on their qualifications. Since 2009, the role is filled by an individual chosen from the nursing team staff and then after three years the role may or may not be renewed by the institution. This has varying implications to the nursing professional and institutions, which may contribute to the understanding of the relationships between nurse-managers and registered nurses (RNs). Despite this historical context, this study does not focus on this event. It is intended to focus not only on the factors of recognition but also on the contrast of nurses to nurse-managers in leadership roles.

\section{METHODS}

\subsection{Research design}

A descriptive cross-sectional study of a qualitative nature, based on the Zavalloni Ego-ecological Theory.

\subsection{Materials}

As the instrument of data collection, this research used the Inventory of the Psychosocial Identity (IIP) of Zavalloni \& Louis-Guérin $^{[6]}$ adapted by Marta, Lopes, Pereira \& Leite, ${ }^{[8]}$ adding sociodemographic data, the Network Analysis Technique Associations and a set of questions in the form of a structured interview.

\subsection{Sampling procedures and sample characterisation}

Interviewed 19 RNs through a non-probabilistic sample by networks, were identified with the inventory number and interview (RN-01 to RN-19). To be included in the study, participants were required to have more than 10 years of practice in a ward setting and experience in hospitals and public health centres in Portugal. Two participants were male and 17 were female, with a mean age of 40 years and service time of 17.8 years; 13 nurses work in hospitals and the rest in health centres; nine nurses worked in nursing specialty roles and four have masters' degrees.

\subsection{Analysis and rigor}

The transcripts were returned to the participants and they were given the option to change them, in order to confirm the accuracy of their transcription. Subsequently, content analysis was carried out according to Bardin, ${ }^{[9]}$ with the construction of dimensions, themes and subthemes, using the NVivo 10 software; the data saturation was considered in the sample size. 


\subsection{Ethical considerations}

All ethical procedures were followed, from the request to use the inventory adapted to the authors, to the disclosure made to participants using oral and written information stating the purpose and objectives of the research, as well as the written authorisation of the participants' interview transcripts.

\section{ReSUlts}

In the interview analysis, the nurses interviewed present a slight differentiation with the nurse-managers, verified by the registry units (67 references of identification and 70 references of differentiation). The results of the categorisation of the Identification and the Differentiation dimensions with the nurse-managers are presented in Table 1.

\subsection{Dimension differentiation with the nurse-managers}

In the dimension of differentiation with the nurse-managers, two themes were constructed, as can be seen in Table 1. The nurses interviewed differ from the nurse-managers primarily in the deficit of competency skills and in the vision of the profession.

Table 1. Identification and differentiation with nurse-managers

\begin{tabular}{llll}
\hline Themes & Sub-themes & Identification & Differentiation \\
\hline $\begin{array}{l}\text { Vision of the } \\
\text { profession }\end{array}$ & $\bullet$ Unity & $\bullet$ Uninformed of care practice \\
& $\bullet$ Participation in care & $\bullet$ Different functions \\
& & $\bullet$ Take care of the team & $\bullet$ Authoritarianism \\
& & $\bullet$ Origin of conflicts \\
& $\bullet$ Technical/Scientific & $\bullet$ Expertise in technical/scientific competencies & $\bullet$ Distance in relation \\
Competency & $\bullet$ Leadership & $\bullet$ Promotion of development & $\bullet$ Managers \\
Skills & $\bullet$ Leaders & $\bullet$ Negotiation \\
& $\bullet$ Management & $\bullet$ Justice & \\
\hline
\end{tabular}

\subsubsection{Deficits of competency skills}

Deficits of competency skills, to which nurses distanced themselves, focus on relational skills, which include authoritarianism, the source of conflicts and distance in the working relationship, followed by management skills.

\section{(1) Relational skills deficits}

Participants report that what distanced them from the nursemanagers is the authoritarianism with which they communicate with the team members. Nurses in this study explained authoritarianism as being the result of economic pressures placed upon the nurse-managers from their hierarchical superiors. These pressures are felt by the nurses when they report that meetings have not taken place for the nursing team to discuss and share ideas and opinions, with nurse-managers having a low tolerance for different opinions and intimidating the nurses, which leads to the nurses feeling insecure about the care they are providing:

“(...) we find very authoritarian leaders, who did not even question anything, they imposed, and we had to fulfill what they imposed without understanding why!” (RN-5).
The nurse-managers were also identified as the origin of conflicts within the team, benefiting some to the detriment of others and when they feel revolted by the pressures exerted on them they put the team in a state of tension and revolt that makes the team of nurses feel dissatisfied and not very committed to their work. One nurse refers to the consequences of these behaviors:

“(... ) less satisfied, as I like being a nurse, I try not to influence, but it consumes a lot more energy, you are less happy, but you try not to let it interfere with the care you provide! I preferred to leave!" (RN-4).

Another characteristic that is referred to as differentiating between nurses and the nurse-managers is the distance in the relations between the nurses and their hierarchy, which is neither appreciated nor desired.

\section{(2) Management skills}

Nurse-managers are visualised by some nurses as manager nurses. Characterised by restraining themselves to their offices, also defined as "public relations of the services", focusing their work on the operational needs of the services. 
The exclusive role of management by the nurse-managers distances them from elements of the team:

"While we are nurses in the active performance of the functions, to take care of the patient, including the positive and negative sides, the nurse-managers have a management role. They are in the office and deal with the nurses, but not with the patients." (RN-16).

\subsubsection{Vision of profession}

The nurses interviewed differ from the nurse-managers because they consider them uninformed with the direct practice of care, considering that some nurses seek the position of leadership to distance themselves from care. Participants state that, as these are nominated, their experiences in the care and technical/scientific knowledge are not valued; therefore, they are not recognised by the nurses they lead as having expertise in care and with competencies to participate in the development of nurses:

“(...) there is a gap of knowledge, of experiences, that does not allow them to be mentors" (RN-18).

According to the nurses interviewed, the nurse-managers should not be distanced from the practice of care, but should cover the areas of care, management and leadership. Nurses recognise that the nurse-managers are often displaced from their areas of work and that this turnover causes problems in recognition by the nurses:

"The problem of the nurse-managers is also this, when people are knowledgeable of the service, they are then being placed elsewhere." (RN-6).

Nurses are distanced from some hierarchical superiors because they visualise them with distinct functions, where the relation with the patient is not included, reserving the functions considered "bureaucratic", which causes rupture with the nursing team:

"They have administrative and bureaucratic functions, basically that, and are always a little apart from the group. It works a little, they are alone on one side and the workgroup is on the other!" (RN-12).

One nurse perceived nurse-managers as obstacles to development, especially in the training of nurses:

“(...) create obstacles when the nurse tries to take a specialty, tries to do something else, when trying to do some training, there are always obstacles instead to providing the conditions for such, on the contrary, there are always obstacles, there are always many complications to doing something." (RN-3).

\subsection{Dimension identification with the nurse-managers}

In the identification, the nurses interviewed are identified in categories of competency skills and vision of the profession (see Table 1).

\subsubsection{Competency skills}

The competency skills, to which nurses approach themselves, predominantly focus on leadership skills followed by management, relational and technical/scientific skills.

\section{(1) Leadership skills}

Nurse-managers, whom the nurses interviewed identify, are recognised as leaders, who do not impose themselves and where their knowledge, experiences and attitudes make them professional mentors for the rest of the team. The nursemanager leader has the ability to stimulate and guide the team to achieve common goals, which means that even if the leader is not present, the team pursues these objectives:

“(...) it is the one that prepares your team to make everything work even if he is not and things are done in the same way, he is not the police nurse, he is not the authoritarian nurse-manager!" (RN-8).

These formal leaders are accepted in the transitional period of identity and professional changes in nurses:

"Most of the nurse-managers I've had are more leaders and have changed my way of being, and now I see nurse-manager more as a leader, they have a more differentiated knowledge and can help the team achieve its objectives." (RN-13).

These figures of formal leaders are perceived as promoting the development of nurses, because when they are motivated they stimulate others, and as they know the elements of the team, they enhance their development, supporting them to increase their knowledge and development of care provided:

"When it promotes the team, it promotes and rewards each of its elements, encourages professional development, knows the members of its team and understands the context that each one needs to grow professionally.” (RN-8).

The connections that nurses' maintain with other professions, and even with society, allow them to use negotiation to defend nurses and the care they provide. This ability to negotiate becomes crucial to the effective and beneficial management of the team itself, by negotiating solutions, arguing their points of view and listening to the arguments of the team members, although not always being able to satisfy all aspects, this figure acts to unify the team and in the:

“(...) sense of giving support, of being able to establish bridges of communication between the nursing and multidisciplinary team when this communication does not exist 
and help to make moments of reflection in certain situations of our practice." (RN-11).

\section{(2) Management skills}

Management skills stand out in the direction of justice and in the activity of managing this in the team.

Participants value nurse-managers who do not make hasty judgments, which do not benefit some elements to the detriment of others, considering these behaviors as showing justice in their leadership attitudes. Nurses, despite recognising that the nurse-managers are leaders, also associate them with management activity:

“(...) has to do with the insight for all these particularities that is to manage groups, to manage the discipline of Nursing to manage the logistics." (RN-1).

\section{(3) Relational skills}

Participating nurses report that they identify with the nursemanagers who take care of the team, who are considered peers, who know the difficulties of the team members and help them overcome them, in addition to caring for people and families. Nurse-managers take care of the team members themselves, serving as support, and leading them to develop personally and professionally:

“(...) take care of other people ... besides the users, the families, and the nurses.” (RN-1).

\section{(4) Technical/scientific skills}

Nurses value the nurse-managers who have updated evidencebased technical/scientific skills through their professional experiences, which they share in the group and which allows them to guide the team:

“(...) look there and see someone who can show experience, sense of security, it has to be the person who is going to impart more experience, more skills, is a person who plays a key role in the team." (RN-19).

\subsubsection{Vision of profession}

Some nurses interviewed, in the vision of profession category, conceive the role of the nurse-manager as a participant in the direct provision of care and that should promote the team's unity.

Nurse-managers, according to the interviewees, should accumulate their managerial and leadership roles through their direct participation in care, differentiating between past and present management:

"I think the older generation was a generation who was there just to send, just to organise the service, they really enjoyed being inside the office. I think the younger nurse-managers

Published by Sciedu Press is already a generation with a difference, is a generation that comes from the practice, who likes to be with colleagues to see how things are done to lead within situations." (RN-6).

Nurses defend the nurse-manager in the unity role,

"The team itself has to recognise this leader as a part of it, has to be unity with him, he has to be comfortable and trust." (RN-13).

\section{Discussion}

The study made it possible to know the influences on these professional nurses from their formal leaders, as well as the obstacles that obstruct this recognition of leadership.

Nurse-managers are characterised by increased power or authority that, according to the interviewees, may be an advantage or a disadvantage, according to their uses and forms of relationships. ${ }^{[5,10]}$

The nurses differ from the nurse-managers who used distance and authoritarianism in their professional relations, which in no way adds value to the team. These behaviors are sometimes justified by nurses because of appointments to this position in Portugal, which provides vulnerability in the economistic pressures on the hierarchical superior of the nurses, thus revealing behaviours consonant with these pressures, not making team leader of nurses but a manager of the institution.

Indeed, some nurses even mention that the job of nursemanager as having different professional functions to those of the nurse, being only restrained to the management. They add that the nurse-managers are not conscious of the influences of practice of care, hence, they are perceived as obstacles to the development of nurses. The need for a nursemanager to be present in a side-by-side capacity with nurses is not only a desire of the interviewed nurses, but it was also noted in another study. ${ }^{[11]}$ In this study, the nurses expected a nurse-manager to be present at all time due to the direct impact that the presence had on the team and care provided, however the authors of this study concluded that this level of presence was unrealistic for the role of the nurse-manager. The study also noted that the participation of nurse-managers in care is effective when healthy interpersonal and supportive relationships with nurses (RNs) mean that the RNs can speak freely about unity or organizational problems, as well as personal or professional difficulties, without the fear of repercussions. ${ }^{[11]}$ Additionally, when nurse-managers recognise the nurses' values, interests, as well as learning and educational needs, it is believed to promote the development of the organization along with the individual nurse's professional development. ${ }^{[12]}$ 
Administrative aspects have always been valued in the duties of the nurse-manager, so that they can control through power; ${ }^{[2]}$ the nurses interviewed relate the use of this control and power by these superiors in response to economic pressures, as in a previous study in Portugal. ${ }^{[10]}$

Because there is currently no career through advertisement for the nurse-managers, entering the category by appointment, it weakens relations with the organisation and other professionals. This situation decreases the authority of the nurse-manager to the other professional actors. ${ }^{[13]}$ According to the interviewees, if a formal position is provided for nurse-managers, it would allow them to act more independently, in the professional practice and as a leader of nurses. This would consequently allow them to use their capacity to defend the nursing profession and care provided before other professions and external pressures.

Despite recognising the need for a professional category, the nurse-managers must be considered leaders by their followers and cannot incur an imposition of this recognition. Leadership is recognised when the nurse-manager, in their professional activity, can be a mentor for the team influencing the team's development and the pursuit of common goals, and maintaining this influence even when they are not present.

With the nomination of the professional role of nursemanager, the nurses recognise the managerial role, but to be perceived as a leader, the nurse-manager needs to be seen as guiding the team in the pursuit of common goals. ${ }^{[14]}$

Nurses identify with the nurse-managers who take care of their team, who consider themselves to be peers, who add to the role of specialised nurse, support the team, help them to overcome difficulties, and promote professional and personal development.

Nurse-managers, to be considered as leaders, require evidence-based technical/scientific competencies at the expert level. Being recognised as an expert by peers, coupled with team relational skills, enables leadership to be developed and enables the recognition as a leader by peers.

The nurse leader needs to have certain competencies that allow this recognition; from the functions of supporting the team (sense of team), promoting the personal and professional development of its people (improvement), to building close relationships with peers. The recognised leader is also required to have technical/scientific skills at the expert level, which enables the team and its professionals to be developed through leadership.

Nurse-managers, acting as leaders, are recognised as promot- ers of the nurses' development, motivating them to improve their care and participation, and encouraging the formation of peers. Another situation considered important in this process of leadership is, for example, the establishment of shared goals, such as promoting the motivation, training and development of the nurse professional and consequently their practices.

The role of developmental promoter can be achieved through clinical supervision, which has professional identity implications and tends to increase commitment to the profession alongside increasing the sense of job satisfaction from education. ${ }^{[15]}$ In clinical supervision, the supervisor should not only hold knowledge but also experience and values which improve practices by promoting innovation in practice, based not only on experiences but also on evidence-based research, leading to them being leaders and innovators of care. ${ }^{[16]}$

Participants mentioned that one of the competencies that the nurse-managers should have is expertise in nursing care, obtained at expert level, ${ }^{[17]}$ which would require the involvement of these leaders in the practice of direct care. This would enable the nurse-managers to recognise difficulties as well as the potential of development and change, both to the nursing care and to the professionals, which would ultimately raise the quality of care provided by the team.

The nursing leader needs, above all, to be a mentor for peers. The interviewed nurses cannot distinguish between the nursemanagers as formal leaders and informal leaders within the team, hoping for a rapprochement. As the nurses work side by side with informal leaders and recognise their clinical expertise, the separation between formal and informal leaders is indistinct; however, the importance of a partnership between these leaders is recognised.

The nurse-manager leader is recognised by technical/scientific and professional expertise, of being present in the relationships, of the promotion of professional development of their followers, and by their direct contact with the RNs and their practices.

The sense of team is present in the recognition of the formal leader, considering that, in addition to professional development and motivation, the unity and intervention in conflict management should be fostered. This considers that conflicts are inherent to the practice of professional health teams, meaning that conflict mediation is an essential role of the leader. ${ }^{[18]}$ Participants want their leaders to nuture healthy work environments, which includes the capability to manage conflict through conflict resolution strategies. On the other hand, leaders and the other members of the team should share responsability in conflict resolution so as not to interfere with 
care and relations among colleagues. ${ }^{[19]}$

Nurses consider that the exclusivity in the management role granted to the nurse-manager is a distancing factor, as well as the non-recognition that the leader's role also includes the functions of human resources, and logistics or materials management. The role of manager is not a distancing factor for nurses when it is present simultaneously with the role of leader; it is the exclusivity of the management role which is the distancing factor.

The nurse leader, develops the potential of their followers, shares leadership, increasing the quality of care through changes and innovations, is considered a mentor and has the capacity, through their leadership, to influence the thoughts and actions of people. ${ }^{[20]}$ Providing development and transformational leadership, by nurturing and sharing leadership, by building partnerships with informal leaders, the lead nurse can transform followers into informal leaders. ${ }^{[14]}$

Lead nurses not only lead, but also foster and support clinical leadership in their followers, so that, together, they create channels for improving nursing care and developing professional skills. This promotes identification with the profession, achieving, in this way implied of all the agents of the team, outcomes to the patients (person), and outcomes at the organisational and professional level.

\section{Conclusions}

Nurse-managers can choose to distance themselves from nurses or, on the contrary, collaborate in their identity transitions, in their professional development and in improving nurses' practices.

For a nurse-manager to be considered a leader, besides the expertise in technical/scientific and relational knowledge in evidence-based research, competencies in leadership and management must coexist with consideration to implications of authority and power which includes being able to exert influence in the group as a professional mentor or leader. Nurses follow leaders who hold the vision that the nursemanager profession has an enormous impact in best practices and inovative care, as well as leaders that encourage team unity in managing conflicts and support nurses in their professional development. It is recognised that the interviewees desire a partnership between formal leader and informal leader to benefit the joint professional development of the remaining elements of the nursing team, and for identity transitions.

\section{Implications and limitations}

The recognition of the approaches and distances to the leadership of the nurse-managers allows an understanding of the factors involved in the professional relations of nurses with their hierarchical superiors. It also allows an understanding of some forms of professional influence of the formal leaders to increase the sense of professional belonging (identity), the professional, and the development of nursing practices. Thus, it is hoped to help nursing leaders in combining efforts with their team as well as contributing to the sense of identity, professional development and nursing practice. This study may help to understand the approaches undertaken by leaders in nursing and also inform future leadership training for nurses.

It would be relevant to expand this study nationally and internationally, to know both the specifics and similarities in the recognition or non-recognition of formal leadership in nurses. The conclusions of this study, which are not generalised, are important for the knowledge of the phenomenon in nurses who work in hospitals and health centres.

\section{CONFLicts OF INTEREST Disclosure}

The authors declare they have no conflicts of interest.

\section{REFERENCES}

[1] Huber D. Leadership and Nursing Care Management. 5th edition. Missouri: Elsevier; 2013.

[2] Marquis BL, Huston CJ. Leadership Roles and Management Functions in Nursing: theory and application. 9th edition. Philadelphia: Wolters Kluwer Health; 2017.

[3] Komives SR, Wendy W. Leadership for a Better World: Understanding the Social Change Model of Leadership Development. 2nd Edition. San Francisco, CA: Jossey-Bass; 2017.

[4] Aarons GA, Ehrart MG, Farahnak LE, et al. Leadership and organizational change for implementation (LOCI): a randomized mixed method pilot study of a leadership and organization development intervention for evidence-based practice implementation. Implemen- tation Science. 2015; 10. https://doi.org/10.1186/s13012-0 14-0192-y

[5] Lavoie-Tremblay M, Fernet C, Lavigne GL, et al. Transformational and abusive leadership practices: Impacts on novice nurses, quality of care and intention to leave. Journal of Advanced Nursing. 2016; 72(3): 582-592. PMid: 26602068. https://doi.org/10.1111/ jan. 12860

[6] Zavalloni M, Louis-Guérin C. Identité sociale et conscience. Introduction à l'égo-écologie [Social identity and conscience. Introduction to ego-ecology]. Montréal: Les Presses de l'Université de Montréal; 1984

[7] Zavalloni M. Ego-écologie et identité: une approche naturaliste [Egoecology and identity: a naturalistic approach]. Paris: PUF; 2007.

[8] Marta M, Lopes A, Pereira F, et al. A relevância profissional da for- 
mação de professores e enfermeiros no ensino superior: uma análise a partir das identidades dos formadores [The professional relevance of initial education of teachers and nurses in higher education]. Revista Lusófona de Educação. 2014; 27: 75-91.

[9] Bardin L. Análise de conteúdo [Content analysis]. 3th ed. Lisboa: Edições 70; 2015.

[10] Fernandes SR. A avaliação de desempenho como estratégia de negociação identitária [The Nurse's Performance Assessment as Strategy for Identity Negotiation]. Revista Educação, Sociedade \& Culturas. 2011; 34: 117-136.

[11] Feather RA, Ebright P, Bakas T. Nurse manager behaviors that RNs perceive to affect their job satisfaction. Nurs Forum. 2015; 50(2): 125136. PMid: 24428342. https ://doi .org/10.1111/nuf . 12086

[12] Govranos M, Newton JM. Exploring ward nurses' perceptions of continuing education in clinical settings. Nurse Educ Today. 2014; 34(4): 655-660. PMid: 23891123. https ://doi.org/10.1016/j . nedt. 2013.07.003

[13] Maciel CMF. Mudança organizacional e liderança em Enfermagem [Organizational Change and Leadership in Nursing]. Master thesis. Aveiro: Aveiro University; 2011.
[14] Weiss SA, Tappen RM. Essentials of Nursing Leadership \& Management. Philadelphia: F.A. Davis Company; 2015.

[15] Ning T, Costello J. Implementing clinical nursing supervision in Singapore hospitals. GSTF Journal of Nursing and Health Care (JNHC). 2017; 5(1).

[16] Garrido A, Simões J, Pires R. Supervisão clínica em Enfermagem perspetivas práticas [Clinical supervision in nursing perspectives practices]. Aveiro: Universidade de Aveiro, Comissão Editorial; 2008.

[17] Benner P. De iniciado a perito [From novice to expert]. 2nd edition. Coimbra: Quarteto; 2005.

[18] McKibben L. Conflict management: importance and implications. British Journal of Nursing. 2017; 12: 100-103. PMid: 28132555 https://doi.org/10.12968/bjon.2017.26.2.100

[19] Baddar F, Salem OA, Villagracia HN. Conflict resolution strategies of nurses in a selected government tertiary hospital in the Kingdom of Saudi Arabia. J Nurs Educ Pract. 2016; 6(5): 91-9. https://doi.org/10.5430/jnep.v6n5p91

[20] Downey M, Parslow S, Smart M. The hidden treasure in nursing leadership: informal leaders. Journal of Nursing Management. 2011; 19: 517-521. PMid: 21569148. https://doi.org/10.1111/j.1365 $-2834.2011 .01253 . \mathrm{x}$ 